\title{
Lipolytic Surface Remnants of Triglyceride-rich Lipoproteins Are Cytotoxic to Macrophages but Not in the Presence of High Density Lipoprotein
}

\author{
A Possible Mechanism of Atherogenesis?
}

Byung Hong Chung, Jere P. Segrest, Kim Smith, Frank M. Griffin, and Christie G. Brouillette

Department of Medicine and Atherosclerosis Research Unit, University of Alabama Medical Center, Birmingham, Alabama 35294

\begin{abstract}
Hypertriglyceridemic (HTG) serum, lipolyzed in vitro by purified bovine milk lipoprotein lipase, was found to be cytotoxic to cultured macrophages. Surviving macrophages contained numerous lipid inclusions similar to those found in foam cells. Individual lipoprotein fractions isolated from the lipolyzed HTG serum, including HDL, were also cytotoxic. Lipolysis of isolated lipoprotein fractions (either HTG or normal) allowed localization of cytotoxicity to postlipolysis remnant VLDL and chylomicron particles. The presence of a critical concentration of HDL in either the lipolysis mixture or the culture dishes inhibited the cytotoxicity. Below this critical concentration HDL itself became cytotoxic, producing lipid inclusions in surviving macrophages. The lipid fraction of the cytotoxic remnants contained the cytotoxic factor(s); neither FFA nor lysolecithin alone could account for this cytotoxicity. Postprandial lipemic sera from subjects with a brisk chylomicron response, when lipolyzed in vitro, were cytotoxic to cultured macrophages; neither fasted sera from these subjects, nor postprandial sera from normolipidemic subjects with a normal chylomicron response, were cytotoxic. Postheparin (in vivo lipolyzed) serum and its isolated lipoprotein fractions obtained 30 min after heparin injection in subjects with HTG were shown to be cytotoxic to macrophages; by 60 min most of the cytotoxicity had disappeared. The postprandial and postheparin observations support an in vivo significance for remnantassociated cytotoxicity. We hypothesize that cytotoxic remnants of lipolyzed VLDL and chylomicrons may be one of the major atherogenic lipoproteins. Further, we suggest that inhibition of the cytotoxicity of these remnants may be one important way that HDL prevents atherosclerosis.
\end{abstract}

\section{Introduction}

Elevated levels of circulating lipoproteins have been implicated as risk factors for the development of atherosclerosis (1). Whereas most attention has been given to LDL as the atherogenic lipoprotein (2), considerable evidence exists that other lipoprotein species may be at least as important as LDL in the pathogenesis of atherosclerosis (3). The basic mechanisms for

This work was presented in part at the American Heart Associations 60th Scientific Sessions, 16-19 November 1987, Anaheim, CA.

Address reprint requests to Dr. Jere Segrest, Atherosclerosis Research Unit, Department of Medicine, UAB Medical Center, Birmingham, AL 35294.

Received for publication 25 January 1988 and in revised form 31 October 1988.

J. Clin. Invest.

(c) The American Society for Clinical Investigation, Inc.

$0021-9738 / 89 / 04 / 1363 / 12 \$ 2.00$

Volume 83, April 1989, 1363-1374 the putative atherogenicity of the different lipoproteins have yet to be clearly defined.

Dietary fat and cholesterol are absorbed from the intestine and secreted into the blood plasma in the form of triglyceride (TG) ${ }^{1}$-rich chylomicrons. Most cholesterol synthesized in the liver enters the plasma in the form of TG-rich VLDL. The initial step of catabolism of both TG-rich lipoproteins in plasma is hydrolysis of the TG of the lipoproteins by lipoprotein lipase $(\mathrm{LpL})$ bound to the endothelial surface of blood vessels (4). One consequence of this LpL-mediated hydrolysis of TG is a rise in the level of HDL through an episodic flux of excess surface components of TG-rich lipoproteins into the plasma HDL fraction (5).

The severity of atherosclerosis in patients with certain types of hyperlipoproteinemias and in cholesterol-fed rabbits has been correlated with the levels of circulating lipolytic remnants of TG-rich lipoproteins, including $\beta$-VLDL (6-10). $\beta$ VLDL and lipolytic remnants of TG-rich lipoproteins incubated in vitro with macrophages produce an accumulation of cholesteryl esters in these cells (11-14), mimicking the appearance of one of the hallmark cells of the atherosclerotic plaque, the macrophage/foam cell. Unmodified LDL incubated with macrophages under the same conditions fails to produce a similar cholesteryl ester accumulation $(11,12)$.

The pathogenesis of the atherosclerotic lesion involves an early stage in which the foam cell is the predominant lesion and a later stage in which necrosis is predominant. Published studies of the role of LDL or TG-rich lipoprotein remnants in atherogenesis have failed to explain adequately the inflammatory/necrotic nature of the atherosclerotic plaque. We show in this paper that lipolytic remnants of TG-rich lipoproteins are not only one cause of foam cell formation in macrophages but are also one cause of necrosis in these same cells, a necrosis that can be inhibited by HDL.

To examine the possible role of lipolytic remnants of TGrich lipoproteins in atherogenesis, we produced lipolytic remnants of TG-rich lipoproteins in vitro by incubating HTG serum or isolated VLDL with purified bovine milk LpL or in vivo by injecting heparin into a hypertriglyceridemic (HTG) human subject. The interactions of these remnant products with cultured mouse peritoneal macrophages were then studied.

\section{Methods}

Materials. Fresh normolipidemic and HTG (type IV and V) plasma or serum was obtained from volunteers and from the Alabama Regional Blood Center, Birmingham, AL. Fresh serum was also obtained from

1. Abbreviations used in this paper: BHT, butylated hydroxytoluene; HTG, hypertriglyceridemic; IDL, intermediate density lipoprotein; LpL, lipoprotein lipase; SVS, single vertical spin; TG, triglyceride; VAP, vertical autoprofile. 
normolipidemic volunteer subjects after an overnight fast (fasted serum) and $4 \mathrm{~h}$ after a fatty meal (postprandial lipemic serum). Two subjects, one with moderate hypertriglyceridemia (fasting TG and cholesterol concentrations of 660 and $308 \mathrm{mg} / \mathrm{dl}$, respectively) and one with mild hypertriglyceridemia (fasting TG and cholesterol concentrations of 232 and $141 \mathrm{mg} / \mathrm{dl}$ ), were recruited for the in vivo lipolysis studies. Lipoprotein cholesterol profiles in these plasmas were examined by the vertical autoprofile (VAP) method developed in this laboratory (15). VLDL, LDL, and HDL fractions were quantitatively fractionated from a portion of the above plasma by the single vertical spin (SVS) density gradient ultracentrifugation method (16). LpL was separated from raw bovine milk and purified by the heparin-Sepharose (Pharmacia Fine Chemicals, Piscataway, NJ) affinity chromatographic method described by Iverius et al. (17). Unstimulated macrophages were harvested from the peritoneal cavities of female white mice (CD1; Charles River Breeding Laboratories, Wilmington, MA) according to the method of Edelson and Cohn (18) and plated in 24-well culture dishes containing cover slips. Human peripheral monocytes and monocyte-derived macrophages were kindly provided by Dr. Marianne Egan at the University of Alabama. Monocytes were prepared from buffy coats of fresh blood by the method of Recalde (19). Cultured human umbilical vein endothelial cells, human skin fibroblasts and rat cardiac myocytes were kindly provided by Dr. Francois Booyse, Dr. Henning Birkendal, and Dr. Larry Bugaisky, respectively, at the University of Alabama.

Lipolysis of serum and lipoproteins. Lipolysis of TG-rich lipoproteins in HTG or normolipidemic serum was performed in vitro by adding purified $\mathrm{LpL}$ into serum $(50 \mu \mathrm{l} / \mathrm{ml}$ serum) and subsequently incubating the mixtures at $37^{\circ} \mathrm{C}$ for $60-90 \mathrm{~min}$. For lipolysis of isolated lipoproteins in vitro, mixtures containing the isolated lipoproteins $(40 \mathrm{mg} / \mathrm{dl}$ VLDL-cholesterol, $80 \mathrm{mg} / \mathrm{dl} \mathrm{LDL-cholesterol,} \mathrm{or} 30$ $\mathrm{mg} / \mathrm{dl} \mathrm{HDL}$-cholesterol) and $6 \%$ fatty acid-depleted BSA were incubated with purified $\mathrm{LpL}(50 \mu \mathrm{l} / \mathrm{ml})$ for $60-90 \mathrm{~min}$ at $37^{\circ} \mathrm{C}$. In certain experiments, butylated hydroxytoluene (BHT) dissolved in ethanol was added to the lipolysis mixture to a concentration of $20 \mu \mathrm{M}$. Isolated $\mathrm{HDL}$ as an acceptor of lipolytic surface remnants of VLDL was also included in lipolysis mixtures containing VLDL and albumin in certain experiments. The level of HDL in the lipolysis mixture was adjusted to give HDL-cholesterol to VLDL-cholesterol ratios of $0.25-2.0$. Incubation mixtures containing heat-inactivated $\mathrm{LpL}\left(70^{\circ} \mathrm{C}\right.$ for $20 \mathrm{~min}$ ) served as the controls. The control and lipolyzed serum or pre- and postlipolysis mixtures containing lipoproteins and BSA were subjected to SVS density gradient ultracentrifugation to fractionated individual lipoprotein fractions or to separated lipoproteins from the BSA.

In vivo lipolysis of TG-rich lipoproteins in serum was performed by intravenous injection of heparin ( $50 \mathrm{IU}$ heparin per $\mathrm{kg}$ body weight) into two fasting HTG volunteers. Blood samples were obtained from these subjects just before (control) and $30 \mathrm{~min}$ and/or $60 \mathrm{~min}$ after the injection of heparin, and serum was separated from the red blood cells. A portion of the control and lipolyzed serum samples were subjected to SVS density gradient ultracentrifugation to fractionate individual plasma lipoproteins.

All samples of serum and fractionated lipoproteins and lipoprotein-deficient plasma fractions were dialyzed against buffered saline ( $0.05 \mathrm{M}$ sodium phosphate- $0.15 \mathrm{M} \mathrm{NaCl}$, or $0.01 \mathrm{M}$ Tris- $-0.15 \mathrm{M} \mathrm{NaCl}$, pH 7.4) to remove $\mathrm{KBr}$ and other salts and were then sterilized by filtering them through $0.45-\mu \mathrm{m}$ membranes (Millipore Corp., Milford, MA). In certain experiments, the antioxidant, butylated hydroxytoluene (BHT) was included in dialysis buffers.

Interaction of lipolyzed serum and lipoproteins with macrophages. Control or lipolyzed serum or lipoproteins (5-150 $\mu$ g cholesterol) were added to culture dishes containing $\sim 10^{6}$ resident macrophages and 1 $\mathrm{ml}$ serum-free DME (Gibco Laboratories, Grand Island, NY), and the dishes were incubated at $37^{\circ} \mathrm{C}$ in a humidified incubation chamber having $5 \% \mathrm{CO}_{2}$ in air for $18 \mathrm{~h}$. At the end of incubation, cover slips containing cell monolayers were removed from the dishes and were washed briefly with buffered isotonic saline to remove the residual lipoproteins or serum components from the cover slips. Cells on the cover slips are then stained with trypan blue by covering the cover slips with $0.4 \%$ trypan blue solution for 3-4 min. After washing off the trypan blue with buffered saline, cover slips were mounted on glass slides, and the number of stained cells and nonstained cells in the several microscopic fields were counted (20). The viability of other cells in monolayer culture (fibroblasts, endothelial cells, and cardiac myocytes) was determined as described for macrophages. The viability of cells in suspension culture was determined as follows: the cells in culture medium were collected by centrifugation of the cell suspensions in conical tubes at $1,000 \mathrm{~g}$ for $5 \mathrm{~min}$. The supernatant fluid was siphoned off and discarded. $0.5 \mathrm{ml}$ of culture media devoid of serum components and $0.1 \mathrm{ml}$ of $0.4 \%$ trypan blue were added to the cell pellet. The mixture was dispersed by use of a Pasteur pipette, and a drop of the suspension was placed on a hemocytometer. The number of stained cells and nonstained cells in a given area on the hemocytometer were counted after 3 min staining of the cells. A minimum of 100 cells were counted.

In certain occasions upon which large number of cells detached from the cover slips, the total number of cells in several microscopic fields of the cover slips from the dishes containing control and lipolyzed was counted and compared. The index of cytotoxicity of lipoproteins to the cells was expressed as a percentage of cells that have excluded trypan blue and a percentage of the cells detached from the cover slips at the termination of the incubation. The inclusion of lipid drops within the cytoplasm of cells was determined after staining the cells with oil red $\mathrm{O}$.

Analysis of lipolyzed serum or lipoproteins. The extent of hydrolysis of TG in lipolyzed samples was determined by measuring TG by the enzymatic TG assay kit (Boehringer-Mannheim reagent set 348202; Biodynamics/BMC Co., Indianapolis, IN) in the pre- and postlipolysis samples after extensive dialysis of the samples. Cholesterol concentration was assayed by the enzymatic method with the reagent set (Set No. 12408; Boehringer Mannheim Biochemicals). FFA concentrations in lipolyzed serum or lipoproteins were assayed by the colorimetric method of Itaya (21). Concentrations of oxidized lipids in dialyzed samples of lipoproteins or serum were estimated by assaying the level of thiobarbituric acid-reacting material as described by Kosuki et al. (22). Lysolecithin was quantitated by measuring phosphorus-containing lipid (23) after separation of lysolecithin from the other phospholipid classes by TLC (24).

Lipid from control and lipolyzed serum or VLDL was extracted with a mixture of chloroform:methanol (2:1, vol/vol). Organic solvents in a portion of the lipid extract was evaporated by use of nitrogen gas, and liposomes were then prepared by sonicating the lipid extract after addition of buffered saline. The other portion of the lipid extracts was applied to an HPLC containing Iatron beads (Astec Co., Whippany, $\mathrm{NJ}$ ), and the column was eluted sequentially with the mixtures of hexane/chloroform/methanol/water/phosphoric acid (282:650:300: 30:4), methanol/water (88:12), and gradient mixtures of cyclohexane and ethyl acetate to fractionate the different classes of lipid. This fractionation was kindly performed by Dr. Walter Shaw at Avanti Polar Lipids, Inc., Birmingham, AL.

Liposomes containing either FFA, lysolecithin, or an individual lipid fraction obtained from the lipid extacts of control and lipolyzed VLDL were prepared by mixing the lipid component with egg phosphatidylcholine and sonicating the mixtures as described earlier. Apolipoproteins in pre- and postlipolysis samples of VLDL were examined by SDS gradient gel electrophoresis (25). The morphology of lipolytic remnants of VLDL was examined by negative staining with $2 \%$ potassium phosphotungstate and examining the grids on a Philips 400 transmission electron microscope.

\section{Results}

Cytotoxicity of in vitro lipolyzed serum and its lipoproteins to macrophages. Incubation of HTG serum in vitro with purified $\mathrm{LpL}$ for $90 \mathrm{~min}$ at $37^{\circ} \mathrm{C}$ usually resulted in the hydrolysis of 


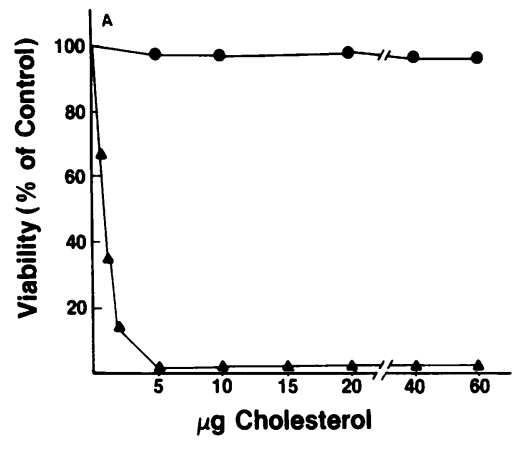

C
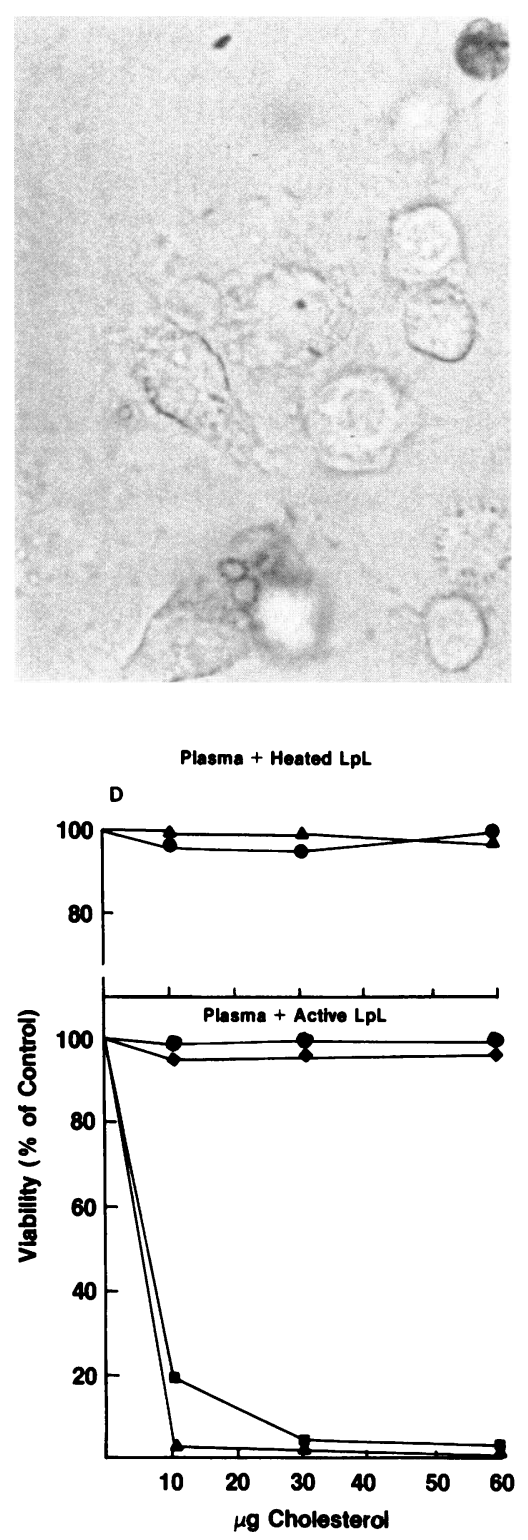
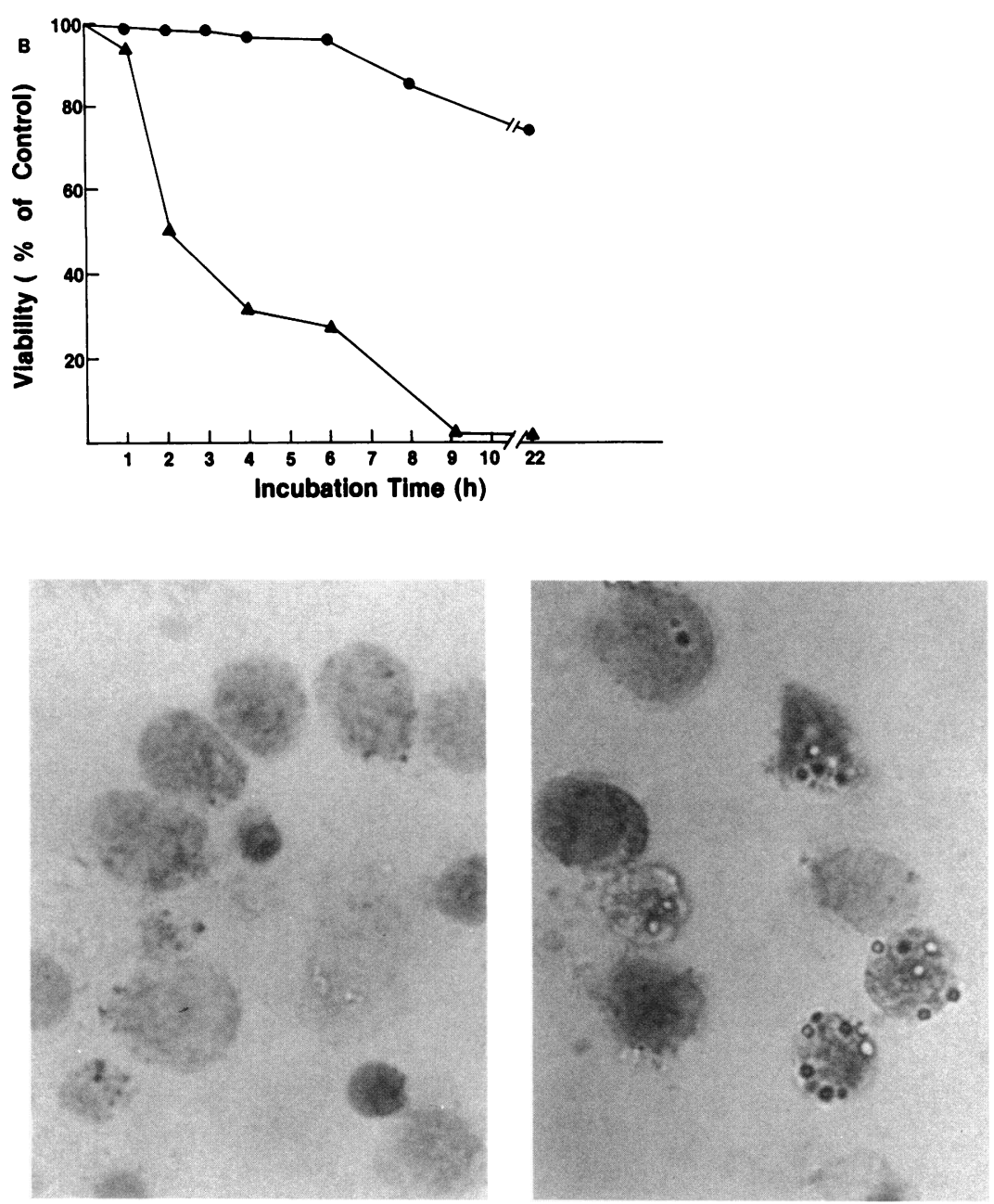

Figure 1. Effects on mouse peritoneal macrophages of HTG plasma lipolyzed in vitro with purified bovine milk LpL. $(A)$ Viability of macrophages incubated with lipolyzed HTG plasma ( $\Delta$ ) versus control HTG plasma (๑). Aliquots of the control or lipolyzed serum containing $1-60 \mu \mathrm{g}$ cholesterol were added to culture dishes containing $1 \mathrm{ml}$ culture medium. After an 18 -h incubation of the dishes at $37^{\circ} \mathrm{C}$ in a humidified incubation chamber, the viability of the cells was examined by counting the percent of cells excluding trypan blue. $(B)$ Changes in viability of macrophages during the incubation after an addition of $10 \mu \mathrm{g}$ cholesterol of control $(\bullet)$ or lipolyzed $(\Delta)$ serum to culture dishes. The culture dishes were withdrawn at the indicated time and the viability of cells was measured as described. $(C)$ Appearance by phase-contrast light microscopy of macrophages after incubation with HTG plasma. (Left) Control HTG plasma (10 $\mu \mathrm{g} /$ dish); (center) lipolyzed HTG plasma (10 $\mu \mathrm{g} /$ dish); (right) lipolyzed HTG plasma $(2 \mu \mathrm{g} /$ dish). The cells were placed on glass cover slips and stained with trypan blue. $(D)$ Viability of macrophages incubated with lipolyzed normolipidemic plasma supplemented with preisolated VLDL. Normolipidemic plasma (VLDL cholesterol $<10 \%$ of total plasma cholesterol) was supplemented with preisolated authen-

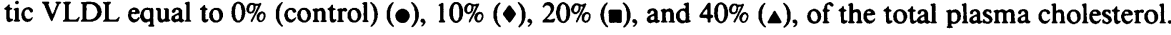
The supplemented plasma was incubated with active (bottom) or heat-inactivated $(t o p)$ LpL. Aliquots of the mixtures $(10,30$, or $60 \mu \mathrm{g}$ cholesterol/dish) were then incubated with macrophages as described above.
$>70 \%$ of the TG in serum. Incubation of this lipolyzed serum with peritoneal macrophages produced an unexpected result. Compared with control serum (incubated with heat-inactivated $\mathrm{LpL}$ ) the lipolyzed serum was highly cytotoxic to the cells. More than $90 \%$ of the macrophages were killed by lipolyzed serum containing 5-10 $\mu \mathrm{g}$ cholesterol per culture dish; control serum at concentrations of up to $60 \mu \mathrm{g}$ per dish had no detectable effect on cell viability (Fig. $1 A$ ). In culture dishes 
A
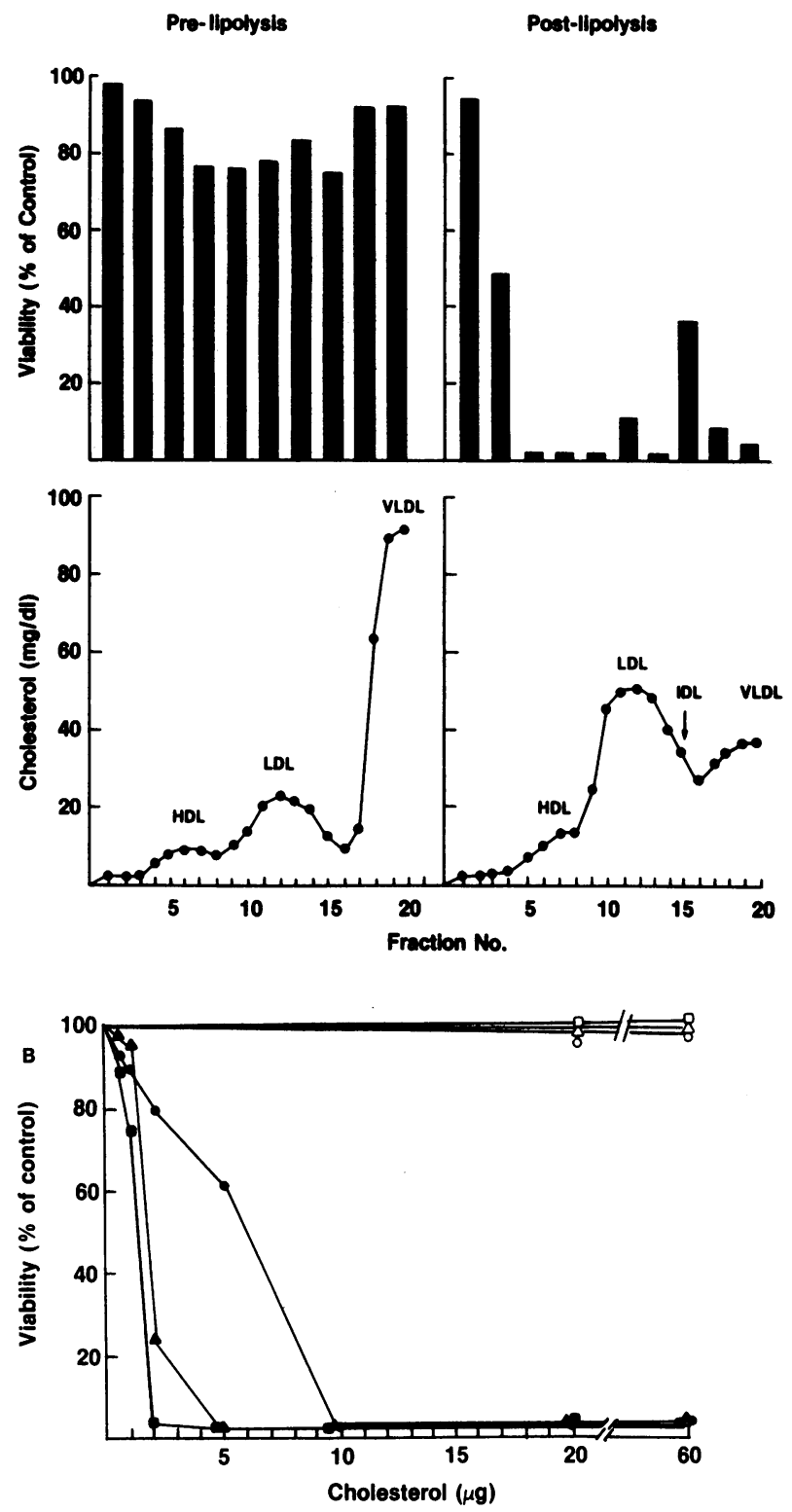

Figure 2. Cytotoxicity of lipoproteins isolated from in vitro lipolyzed HTG serum to macrophages. $(A)$ Viability of macrophages incubated with individual lipoprotein fractions isolated by density gradient ultracentrifugation from pre- and postlipolysis HTG plasma. The preand postlipolysis plasma samples were subjected to SVS ultracentrifugation, and aliquots containing $40 \mu \mathrm{g}$ cholesterol (nonlipolyzed plasma) and $10 \mu \mathrm{g}$ cholesterol (lipolyzed plasma) were removed from the even numbered gradient fractions and added to the culture dishes of macrophages. Aliquots of fractions 2 and 4, containing lipoprotein-free plasma proteins, were based on volume $(50 \mu \mathrm{l})$. Cell viability was then measured after $18 \mathrm{~h}$ incubation as described earlier. (B) Viability of macrophages incubated with varying levels of VLDL (๑), LDL ( $)$, and HDL ( $\bullet$ ), separated from in vitro lipolyzed HTG serum. Viability after incubation with control lipoproteins separated from unlipolyzed serum is indicated with corresponding open symbols.

containing a high concentration of the lipolyzed serum $(>40$ $\mu \mathrm{g} / \mathrm{dish}) \mathrm{a}$ large number of cells in the culture dish were detached from the cover slips and presented in the culture dish as cell debris (data not shown).
Approximately $50 \%$ of the cells were killed within $2 \mathrm{~h}$ and $100 \%$ of cells were killed within $9 \mathrm{~h}$ after addition of the lipolyzed serum to the culture dishes (Fig. $1 B$ ).

Light microscopic examination of cultured macrophages incubated with a sublethal dose of lipolyzed serum ( $2 \mu \mathrm{g}$ cholesterol/dish) showed the presence of numerous lipid inclusions, resembling those seen in foam cells, within the cytoplasm of the surviving macrophages (Fig. $1 C$ ).

Normolipidemic serum was lipolyzed under identical conditions as HTG serum and incubated with macrophages. Neither cytotoxicity nor foam cell formation was observed (Fig. 1 $D$ ). However, when this plasma was supplemented with preisolated VLDL and the supplemented plasma incubated with LpL, the resultant product was both cytotoxic and foam cell inducing; cytotoxicity was found to be dependent on the level of VLDL supplementation (Fig. 1 D).

Control and lipolyzed HTG serum were fractionated by SVS into VLDL, LDL, HDL, and free protein, and each of these fractions incubated with macrophages. All of the lipoprotein fractions from in vitro lipolyzed plasma $(10 \mu \mathrm{g}$ cholesterol) were both cytotoxic and foam cell inducing (Fig. $2 \mathrm{~A}$ ); the free protein fraction was not cytotoxic but induced a modest number of lipid inclusions. Corresponding control plasma fractions, at four times greater concentrations ( $40 \mu \mathrm{g}$ cholesterol), were neither cytotoxic nor foam cell inducing (Fig. $2 A$ ). Based on the relative cytotoxicity of these individual lipoprotein fractions, HDL was the most cytotoxic fraction in the lipolyzed HTG serum (Fig. 2 B).

Cytotoxicity of postprandial lipemic serum from normolipidemic subjects. Ingestion of a fatty meal by normotriglyceridemic subjects resulted in an $\sim 380 \mathrm{mg} / \mathrm{dl}$ increase in plasma TG and a $10 \mathrm{mg} / \mathrm{dl}$ increase in plasma cholesterol $4 \mathrm{~h}$ after the meal in the subject with a brisk chylomicron response but resulted in only a $33 \mathrm{mg} / \mathrm{dl}$ increase in TG with little or no change in plasma cholesterol in the subject with a normal chylomicron response (Fig. $3 \mathrm{~A}$ ). The increase in cholesterol was associated exclusively with an increase in cholesterol in the VLDL density region of the plasma (Fig. $3 A$ ). In vitro lipolysis produced little or no cytotoxicity in fasted or postprandial serum from the normal responder and in fasted serum from the brisk responder. However, the postprandial serum from the brisk responder after in vitro lipolysis was highly cytotoxic to cultured macrophages (Fig. $3 \mathrm{~B}$ ).

Cytotoxicity of in vivo lipolyzed serum and its lipoproteins to macrophages. Heparin injection into mild and moderately severe HTG subjects resulted in hydrolysis of 65 and $68 \%$ of serum TG within $30 \mathrm{~min}$ after injection, respectively. The extent of serum TG hydrolysis $60 \mathrm{~min}$ after injection of heparin in the moderately severe HTG subject was similar to that seen at $30 \mathrm{~min}(68 \mathrm{vs} .71 \%)$. Lipoprotein cholesterol profiles of pre- and postheparin serum showed that $\sim 40-50 \%$ of VLDL-cholesterol in serum from the moderately severe HTG subject (Fig. $4 A$ ) and $\sim 75 \%$ of VLDL cholesterol in serum from the mildly HTG subject (Fig. $4 D$ ) were moved into the intermediate density lipoprotein (IDL), LDL, and HDL density regions.

When pre- or postheparin serum was added to the cultured macrophages, the postheparin serum obtained at $30 \mathrm{~min}$ from the moderately severe HTG subject was highly cytotoxic and foam cell inducing; $>90 \%$ of the macrophages were killed with $10 \mu \mathrm{g}$ (cholesterol) of serum (Fig. $4 \mathrm{~B}$ ). The preheparin serum, even at five times the concentration of postheparin serum, was 


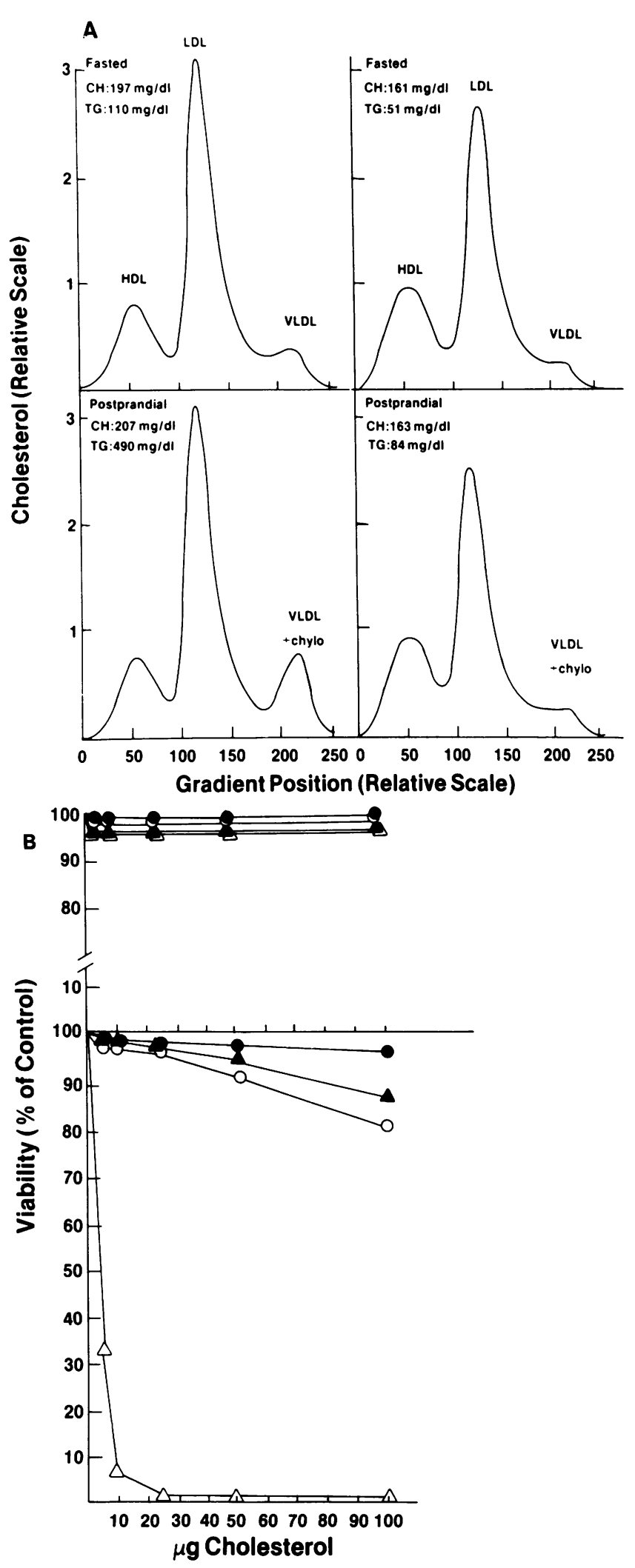

Figure 3. Effects of postprandial lipemia on lipoprotein cholesterol profiles and cytotoxicity of lipolyzed serum. $(A)$ VAP lipoprotein cholesterol profiles of fasting and postprandial lipemic serum: brisk chylomicron responder (left) and normal chylomicron responder $(r i g h t)$. (B) Viability of macrophages incubated with (top) prelipolysis serum or (bottom) postlipolysis serum: fasting $(0)$ or postprandial lipemic $(\Delta)$ serum from the brisk responder and fasting $(\bullet)$ or postprandial lipemic $(\Delta)$ serum from the normal responder. not cytotoxic to the cells (Fig. $4 \mathrm{~B}$ ); only a few lipid inclusions were detectable in these cells. The postheparin serum obtained at 60 min was only marginally cytotoxic to the cells (Fig. $4 \mathrm{~B}$ ), although the extent of hydrolysis of TG in this serum was slightly greater than that in the postheparin serum obtained at $30 \mathrm{~min}$. These results suggest that the cytotoxic components of lipolyzed serum can be produced in vivo but are removed rapidly from the circulation. However, macrophages incubated with postheparin serum obtained at $60 \mathrm{~min}$ had approximately as many lipid inclusions as macrophages incubated with 30 min postheparin serum (data not shown). Postheparin serum from the mildly HTG subject was also cytotoxic to cultured macrophages, but the cytotoxicity of this serum was considerably less than the postheparin serum from the moderately severe HTG serum (Fig. $4 E$ ).

Pre- and postheparin HTG sera from the moderately severe HTG subject were fractionated by SVS into VLDL, LDL, HDL, and free protein and each of these fractions incubated with macrophages. HDL, IDL, and to a lesser extent VLDL were considerably more cytoxic than the LDL fraction (Fig. 4 $C)$. However, cells incubated with LDL fraction were shown to contained numerous lipid inclusions (data not shown). The lipoprotein free plasma fraction from the postheparin serum was not cytotoxic but caused a few lipid inclusions within the cells (Fig. $4 \mathrm{C}$ ). None of the preheparin HTG serum fractions were cytotoxic (Fig. $4 C$ ).

Contribution of individual plasma fractions to postlipolysis cytotoxicity. To examine the contribution of the individual lipoprotein components of plasma to the cytotoxicity of lipolyzed HTG plasma, we isolated VLDL, LDL, and HDL fractions from normolipidemic or HTG plasma and incubated the individual lipoproteins with $\mathrm{LpL}$ in the presence of fatty aciddepleted BSA. In these experiments only, the VLDL fraction was cytotoxic to the mouse peritoneal macrophages and foam cell inducing (Fig. $5 \mathrm{~A}$ ). Examination of the morphology of LpL-induced remnant VLDL by negative stain electron microscopy (Fig. $5 \mathrm{~B}$ ) showed that these remnants were composed of a mixture of liposome-like electron-lucent vesicles and spheroidal IDL- and LDL-sized lipoprotein particles containing attached electron-lucent vesicles.

We previously showed that incubation of HTG plasma with $\mathrm{LpL}$ in vitro resulted in the transfer of a major portion of VLDL remnant surface components (phospholipid, unesterified cholesterol, and apolipoproteins $C$ ) to the HDL density region (26). As shown in Fig. $5 \mathrm{~B}$, remnants produced in the presence of HDL are composed entirely of IDL- and LDLsized lipoprotein particles containing little or no vesicular material. Analysis of the apolipoprotein composition of the LpLinduced remnant VLDL by SDS gradient gel electrophoresis (Fig. $4 C$ ) showed that the remnants produced in the absence of HDL contained essentially all of the apolipoprotein C, whereas the remnants produced in the presence of HDL contained essentially no apolipoprotein C. As shown previously in Fig. $2 B$, when HTG plasma was incubated with $\mathrm{LpL}$ and the cytotoxicity of the isolated lipoprotein fractions measured, HDL was more cytotoxic to the macrophages than either LDL or VLDL ( $100 \%$ killing at 2,5 , and $10 \mu \mathrm{g}$ cholesterol per dish, respectively). These results suggest that HDL may be especially effective in uptake of the cytotoxic factor(s) from remnant VLDL and that the VLDL remnant surface components transferred to HDL under these conditions probably contain the cytotoxic factor(s). One of the major differences between 

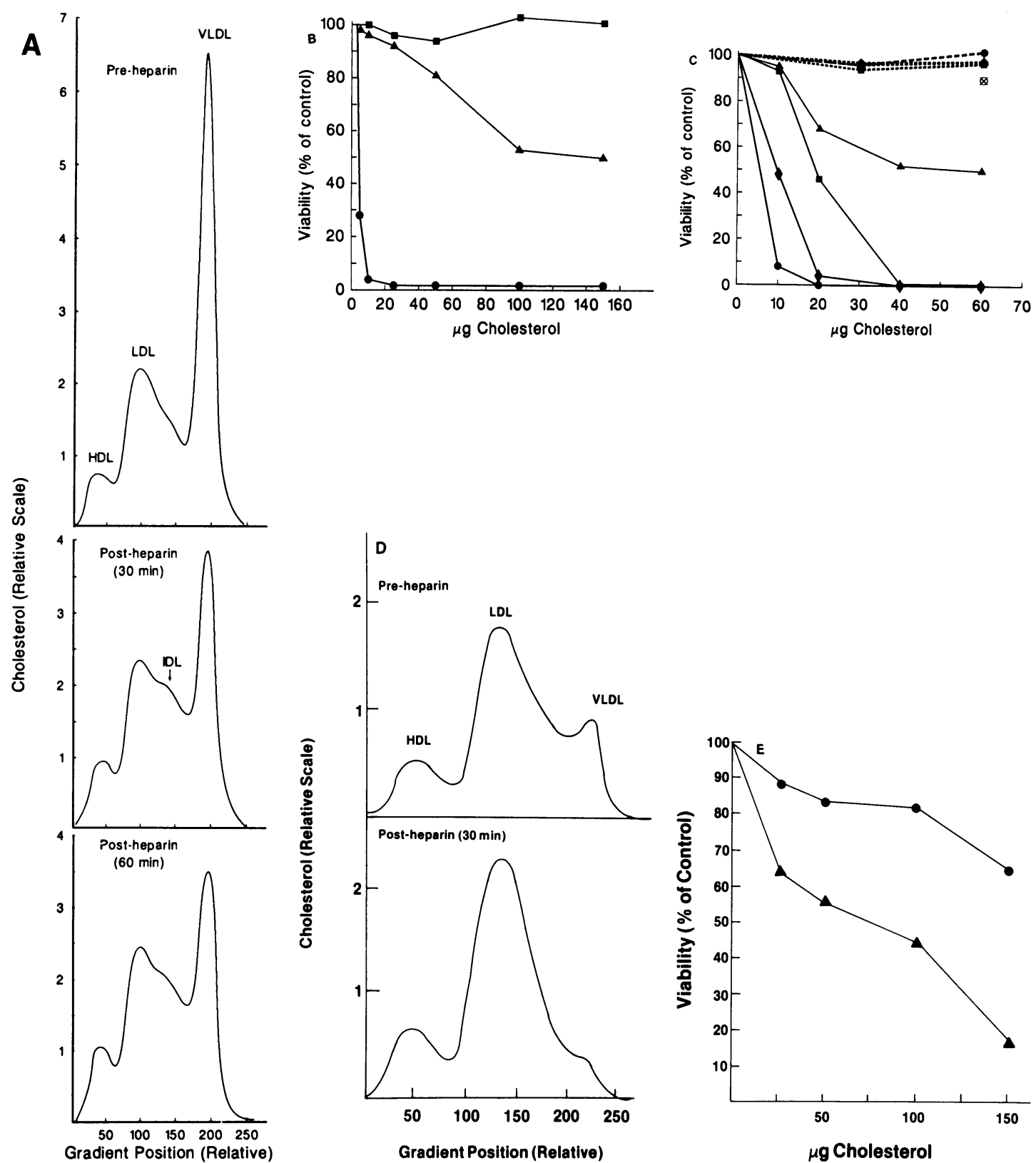

Figure 4. Effects of postheparin in vivo lipolysis on serum and its lipoproteins from two subjects with differing degrees of HTG. Subject with moderately severe HTG. $(A)$ VAP lipoprotein cholesterol profiles of preheparin and postheparin serum. $(B)$ Viability of macrophages incubated with pre- or postheparin serum. Culture dishes containing increasing amounts of preheparin serum ( $\square$ ), or postheparin serum obtained at 30 $\min (\bullet)$, and $60 \mathrm{~min}(\Delta)$, were incubated for $18 \mathrm{~h}$ and the viability of cells was determined. $(C)$ Viability of macrophages incubated with various lipoprotein fractions isolated from pre- and postheparin HTG serum. Culture dishes containing increasing amounts of VLDL ( $\bullet$ ), IDL ( $\bullet$ ), LDL $(\triangle)$, HDL (๑), or 200- $\mu$ l lipoprotein-free serum $(\otimes)$ obtained from postheparin (30 min) serum were incubated for $18 \mathrm{~h}$ and the viability of the cells was measured. Viability after incubation with control lipoproteins separated from preheparin serum is indicated with corresponding symbols and dotted lines. Subject with mild HTG. (D) VAP lipoprotein cholesterol profiles of preheparin and postheparin serum. $(E)$ Viability of macrophages after incubation with preheparin serum $(\bullet)$, or postheparin serum $(\mathbf{\Delta})$.

HTG and normal plasma is a lower HDL to VLDL ratio in HTG. Therefore, we considered the possibility that HDL would inhibit the cytotoxicity of lipolyzed remnant VLDL at higher HDL to VLDL ratios.

Effects of HDL on macrophage viability. To test the possibility that HDL would inhibit the cytotoxicity of lipolyzed remnant VLDL at higher HDL to VLDL ratios, we produced the lipolytic remnants of VLDL in the presence of increasing concentrations of HDL in the lipolysis mixture, and the cytotoxicity and structure or composition of the VLDL remanants were further determined. As shown in Fig. $6 \mathrm{~A}$, HDL did indeed reverse the cytotoxicity of lipolyzed remnant VLDL. At HDL to VLDL ratios of 1.0 or lower, both the remnant VLDL and the HDL isolated from the lipolysis mixtures were cytotoxic, killing $60 \%$ or more of the cells. However, at ratios of 2.0 or greater, the cytotoxicity of both the remnant VLDL and the 
postlipolysis HDL fractions approached that of the controls. Normolipidemic plasmas have HDL to VLDL ratios of four or greater. When HDL was added directly to the culture dishes (Fig. $6 \mathrm{~B}$ ), inhibition of cytotoxicity was even more impressive; complete protection, comparable to controls, was provided by the addition of HDL at a HDL to VLDL ratio of 2.0. The addition of LDL directly to the culture dishes at up to six times the effective concentration of HDL had no measurable effect on remnant VLDL cytotoxicity (Fig. $6 \mathrm{~B}$ ), indicating that inhibition of cytotoxicity is unique to HDL among the lipoprotein classes.

Additional experiments indicated that serum albumin at twice physiological concentrations provided minimal protection (20\% viability) from cytotoxicity (Fig. $6 \mathrm{~A}$ ). Because the levels of albumin in plasma are less variable than those of TG-rich lipoproteins or HDL, because the physiological levels of albumin in whole HTG plasma failed to provide protection from post-lipolysis cytotoxicity, and because the postheparin HTG serum was cytotoxic at $30 \mathrm{~min}$, the protection provided in vivo by albumin may be of considerably less physiological significance than that provided by HDL.

Characterization of cytotoxic components. As a first step in characterization of the cytotoxic factor(s) in lipolyzed VLDL, we extracted the lipid of control and lipolyzed VLDL with the mixtures of chloroform-methanol (2:1, vol/vol). After removal of the solvent and sonication of the lipid in aqueous suspension, the two lipid extracts were incubated with macrophages. The lipid from the lipolyzed VLDL on a per microgram cholesterol basis was somewhat more cytotoxic as compared with that of the original lipolyzed VLDL, whereas the lipid from the control VLDL was essentially noncytotoxic (Fig. $7 A$ ). The lipid-free apolipoprotein components of both VLDL fractions were noncytotoxic (data not shown).

We have begun a preliminary characterization of the factor(s) in the lipid components of the VLDL remnants (presumably localized to the vesicular surface material) responsible for macrophage cytotoxicity. A number of studies have suggested that LDL-containing peroxidized lipid is cytotoxic to cells in culture $(27,28)$. We have examined the level of oxidized lipids in control and lipolyzed VLDL or HTG serum and determined the effect of including antioxidant (BHT) during lipolysis and dialysis of the sample. We found that lipolysis has no effect on the level of oxidized lipid, as judged by the changes in level of thiobarbituric acid-reacting material in the dialyzed samples of control and lipolyzed VLDL or HTG serum (Table I). Further, inclusion of BHT during lipolysis and subsequent dialysis of the lipolyzed HTG serum had no effect on the cytotoxicity of lipolyzed HTG serum (Table I).

FFA and lysolecithin are known products of lipolysis by LpL (29) and are potentially cytotoxic. Unesterified cholesterol has been implicated as a potential cytotoxic and atherogenic substance (30). We have examined the levels of FFA, lysolecithin, and unesterified cholesterol in lipolyzed VLDL and the cytotoxic effect of these lipids to cultured macrophages.

The levels of FFA and lysolecithin in the remnants of VLDL produced in the presence of a physiological level of albumin in the lipolysis mixture are three to four times greater than those in control VLDL. The concentration of FFA associated per milligram cholesterol of control VLDL and remnant VLDL was 40 and $176 \mu \mathrm{g}$, respectively, and the concentration of lysolecithin was 23 and $73 \mu \mathrm{g}$, respectively. The level

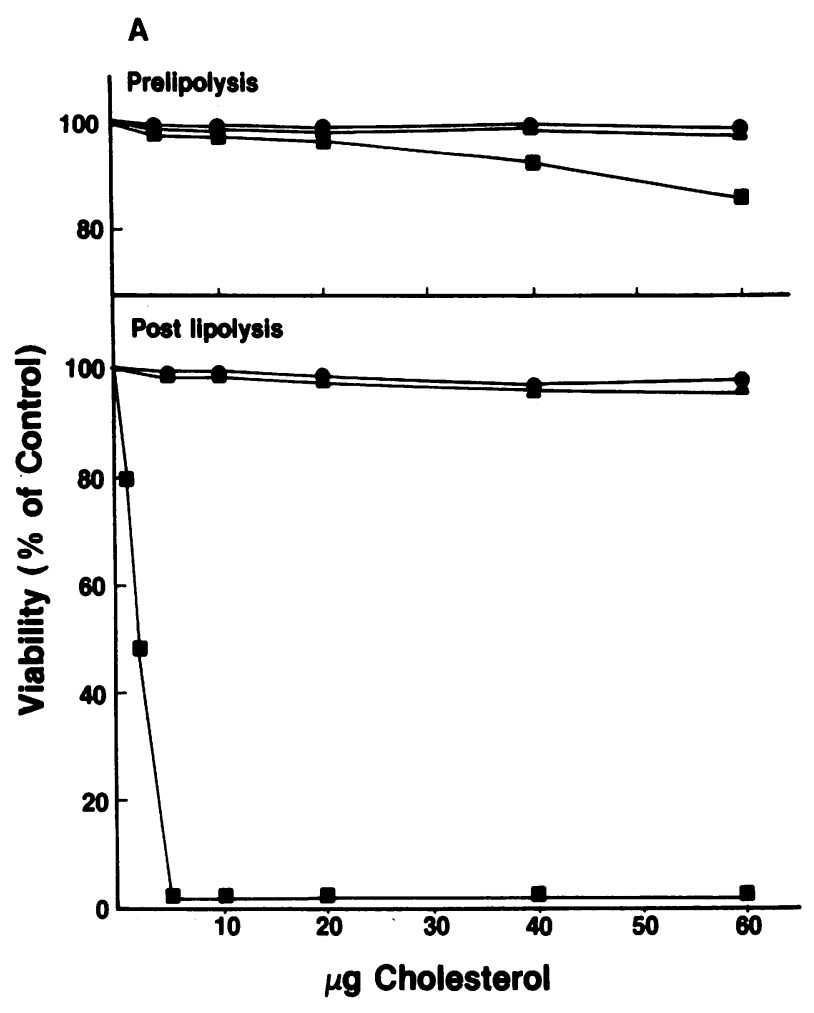

Figure 5. Contribution of individual plasma lipoprotein fractions to postlipolysis cytotoxicity. $(A)$ Viability of macrophages incubated with pre- or postlipolysis samples of preisolated VLDL ( $\bullet$ ), LDL ( $\mathbf{\Delta})$, or HDL (๑). Isolated individual lipoprotein fractions were incubated with $\mathrm{LpL}$ in the presence of BSA for $1 \mathrm{~h}$ at $37^{\circ} \mathrm{C}$. The lipoprotein fraction was then separated from BSA by SVS density gradient ultracentrifugation and added to the culture dishes. $(B)$ Negative stain electron microscopic examination of the products of the lipolysis of VLDL in the presence and absence of HDL. VLDL $(0.4 \mathrm{mg}$ cholesterol $/ \mathrm{ml}$ ) was incubated with $\mathrm{LpL}$ and fatty acid-depleted albumin $(6 \%)$ in the absence or presence of HDL $(0.8 \mathrm{mg}$ cholesterol $/ \mathrm{ml})$. The products of lipolysis were fractionated by SVS density gradient ultracentrifugation, and the morphology of remnants of VLDL was examined by electron microscopy. (1) Control VLDL; (2) control LDL; ( 3 and 6 ) whole lipolysis mixtures; (4 and 7 ) remnants recovered in the VLDL density region; ( 5 and 8 ) remnants recovered in the IDL and LDL density region. $(C)$ SDS gradient gel analysis of apolipoproteins of the lipolytic remnants of VLDL produced in the presence and absence of HDL. The products were identical to those examined by electron microscopy as described above. (1) Control VLDL; (2) remnants recovered in the VLDL density region, produced in the absence of HDL; (3) remnants recovered in the IDL-LDL density region, produced in the absence of HDL; (4) remnants recovered in the IDL-LDL density region, produced in the presence of HDL.

of unesterified cholesterol in VLDL remnants was not detectably different from that in control VLDL.

When the level of lipoproteins in culture dishes were standardized based on the contents of FFA or lysolecithin, only lipolyzed VLDL was cytotoxic to the macrophages (Fig. $7 B$ ). Sonicated egg lecithin liposomes containing FFA, lysolecithin, or unesterified cholesterol were not cytotoxic to the cultured macrophages even at two to three times the concentration of FFA, lysolecithin, or unesterified cholesterol in lipolyzed VLDL (Fig. 7 B). The liposomes containing FFA were, however, foam cell producing (data not shown). 
B

\section{Control Plasma Lipoprotein}

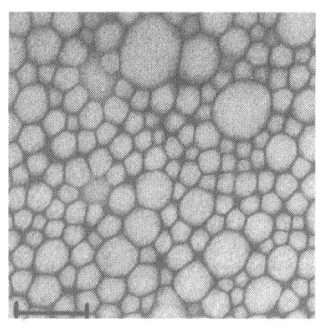

1

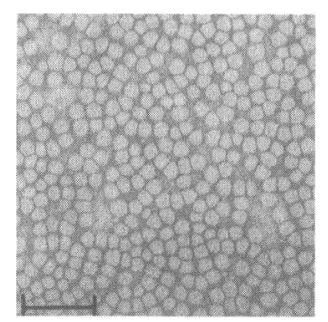

2

\section{Lipolized VLDL (VLDL + Albumin + LPL)}

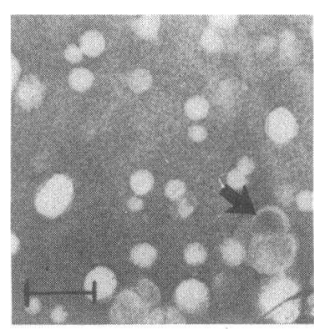

3

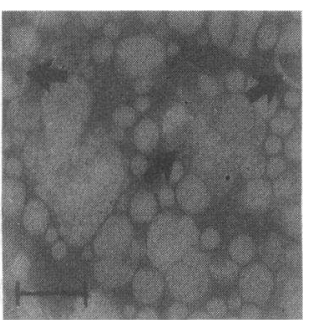

4

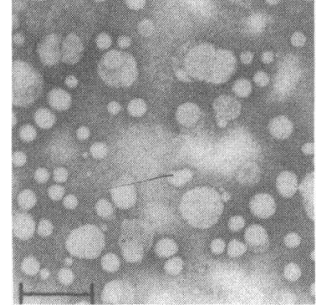

5

Lipolyzed VLDL (VLDL + HDL + Albumin + LPL)

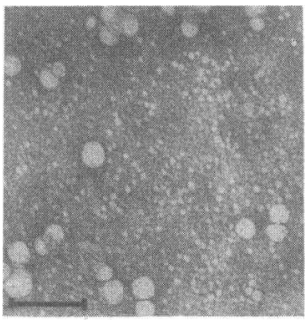

6

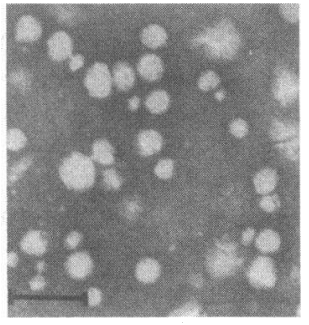

7

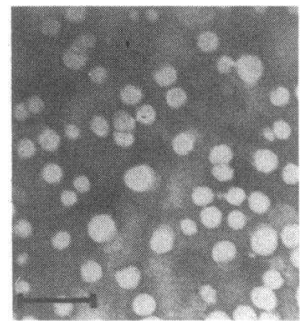

8

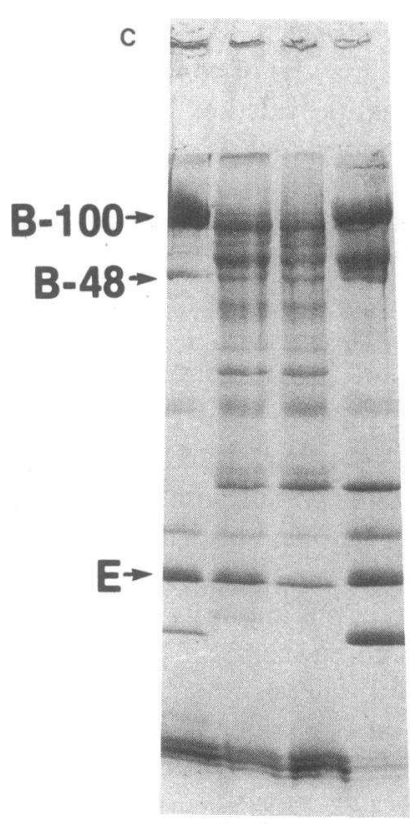

A B C D

Figure 5 (Continued)

Analysis of FFA in pre- and postheparin HTG serum showed that the 30-min sample contained less FFA (556 $\mu \mathrm{mol} / \mathrm{dl})$ than the 60 -min sample $(612 \mu \mathrm{mol} / \mathrm{dl})$ but was significantly more cytotoxic than the 60 -min sample (Fig. 4 B). Further, the 60 -min postheparin serum contained six times as much FFA as the preheparin control serum $(124 \mu \mathrm{mol} / \mathrm{dl})$ but showed very little cytoxicity to macrophages (Fig. $4 \mathrm{~B}$ ). Analysis of FFA concentration in the plasma fractions of pre- and 30-min postheparin serum showed that the plasma free protein fraction contained most of the FFA increase in the serum $(\sim 50 \%$ ) but was not cytotoxic to the macrophages (Fig. $4 C$ ).

At physiological concentrations, albumin and HDL were found to be equally effective in removal of both FFA and lysolecithin from VLDL remnants. Because HDL is considerably more effective than albumin in inhibition of cytotoxicity (Fig. $6 \mathrm{~A}$ ), neither FFA nor lysolecithin seem likely to be the cytotoxic agent(s). Preliminary characterization of the cyto- toxic component(s) in the lipid extract of lipolyzed VLDL by HPLC indicates that component(s) having a solvent mobility between phospholipid and FFA are most cytotoxic to the macrophages. The identity of these component(s) are presently unknown but are currently under investigation in this laboratory.

\section{Discussion}

We demonstrate in this study that lipolysis of TG-rich lipoproteins in vitro or in vivo results in remnants that are cytotoxic and foam cell inducing when incubated with cultured macrophages. Although incubation of isolated LDL or HDL with $\mathrm{LpL}$ fails to cause these lipoproteins to become cytotoxic, lipolysis of whole serum can cause the HDL fraction, and to a lesser degree, the LDL fraction, to become cytotoxic and foam 

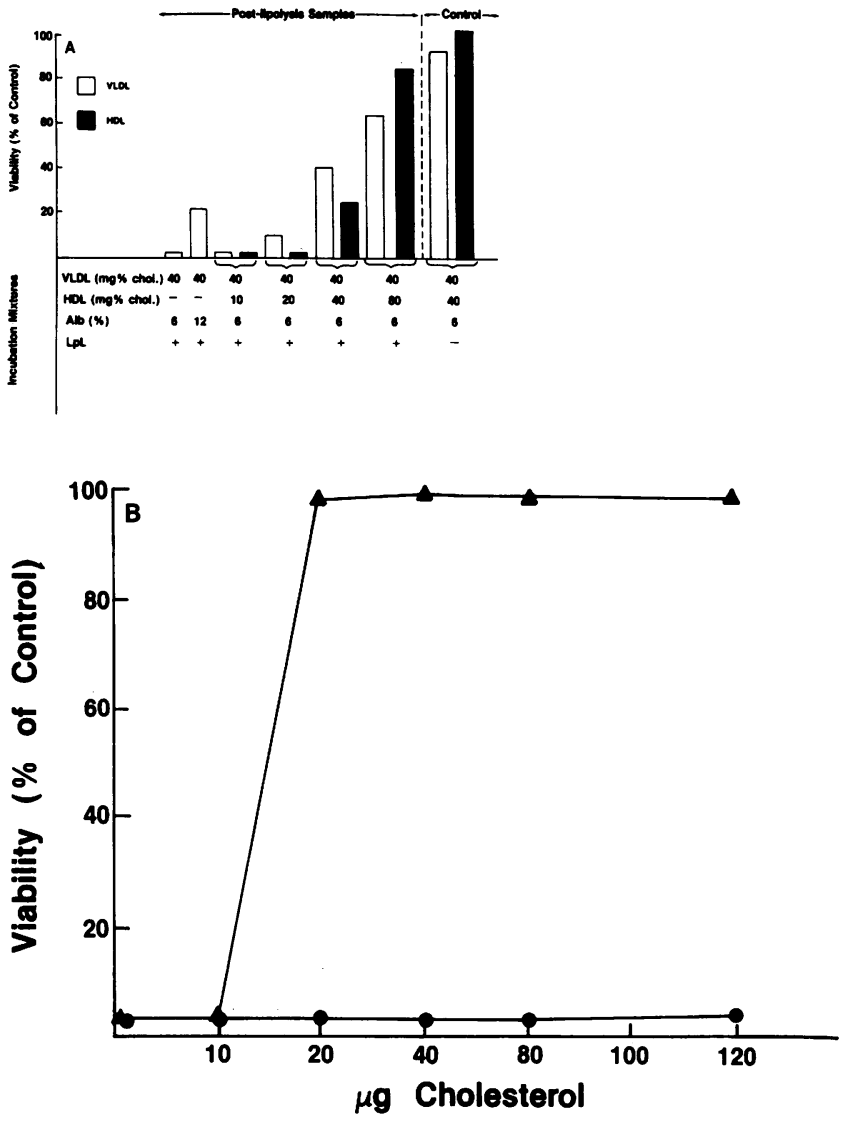

Figure 6. Effects of HDL on macrophage viability. $(A)$ Effects on macrophage viability of the presence of HDL during lipolysis of VLDL. VLDL was lipolyzed with $\mathrm{LpL}$ at $37^{\circ} \mathrm{C}$ for $90 \mathrm{~min}$ in the presence of increasing amounts of HDL and/or albumin. The VLDL remnants and HDL (10 $\mu \mathrm{g}$ cholesterol), separated from BSA, were then incubated with macrophages for $18 \mathrm{~h}$ at $37^{\circ} \mathrm{C}$ and the viability of the macrophages determined. $(B)$ Effects on macrophage viability of the presence of HDL in the culture dish during incubation of lipolyzed remnants of VLDL with the macrophages. Macrophage viability was determined after incubation for $18 \mathrm{~h}$ at $37^{\circ} \mathrm{C}$ of macrophage culture dishes containing $10 \mu \mathrm{g}$ cholesterol of lipolyzed VLDL plus

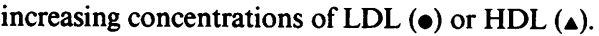

cell inducing. This effect on HDL seems likely to be due to enrichment of HDL with surface remnant products of lipolyzed TG-rich lipoproteins.

In preliminary studies, a number of cell types in addition to mouse peritoneal macrophages have been examined (Table II). Lipolyzed TG-rich lipoproteins and HTG serum are cytotoxic to human monocyte-derived macrophages but, interestingly, not to the monocytes themselves. Further, lipolyzed VLDL is cytotoxic to the macrophage-like J774 cell line but only at a dose seven times higher than needed to kill mouse or human macrophages (Table II). Lipolytic remnants are not cytotoxic to human skin fibroblasts and rat cardiac myocytes.

Finally lipolyzed VLDL is cytotoxic to cultured human umbilical cord endothelial cells (31). Because injury of the arterial endothelial cell is considered an early event in the development of atherosclerosis (32), these preliminary studies suggest the possibility that the cytotoxic and foam cell-inducing lipolytic remnants of TG-rich lipoproteins may play a role in the development of atherosclerosis. It is apparent from
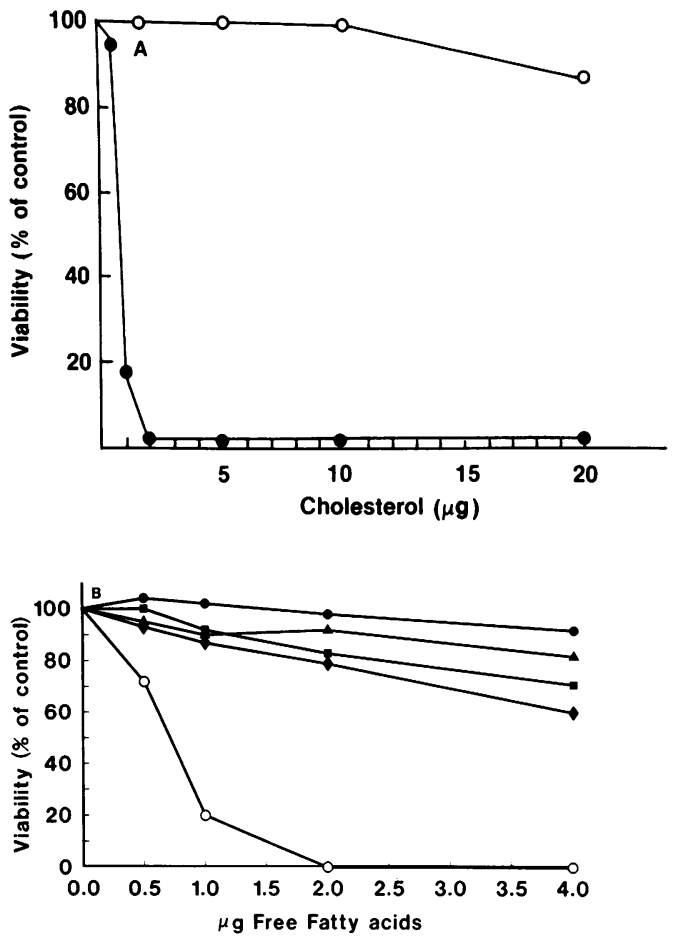

Figure 7. Characterization of cytotoxic components. $(A)$ Effects of lipid extracts of prelipolysis VLDL (O) or postlipolysis VLDL (•) on viability of macrophages. Total lipid was extracted from pre- and postlipolysis samples of VLDL by the chloroform/methanol (2:1, $\mathrm{vol} / \mathrm{vol}$ ) procedure and the solvent evaporated under streams of nitrogen. The lipid residue was sonicated for $20 \mathrm{~min}$ under nitrogen and added to the macrophage culture dishes. $(B)$ Effects of increasing FFA concentrations in control VLDL ( $\bullet)$, control LDL (४), control HDL (๑), lipolyzed VLDL remnants (०), or liposomes ( $\bullet$ ) on viability of macrophages. Control VLDL ( $40.3 \mu \mathrm{g} \mathrm{FFA} / \mathrm{mg}$ cholesterol), control LDL (17.8 $\mu \mathrm{g} \mathrm{FFA/mg} \mathrm{cholesterol),} \mathrm{control} \mathrm{HDL} \mathrm{(57.0} \mu \mathrm{g} \mathrm{FFA/}$ mg cholesterol), lipolyzed VLDL remnants (176.5 $\mu \mathrm{g} \mathrm{FFA/mg} \mathrm{cho-}$ lesterol), or phospholipid (egg phosphatidylcholine) liposomes containing $20 \%$ FFA (oleic acid) were standardized by FFA concentration and added to culture dishes of macrophages.

Table II that lipolyzed lipoproteins and serum appear to be less cytotoxic to endothelial cells than to macrophages. It is also apparent that the in vitro or in vivo (postheparin) lipolysis experiments described here are exaggerations of both the rate and concentration of products of in vivo lipolysis. However, it must be remembered that atherosclerosis under most conditions is a subtle and slowly progressing disease. The chronic nature of this disease is, therefore, entirely compatible with an atherogenic role for lipolytic remnants.

What is the molecular basis for this cytotoxicity? Among the possibilities are the following: (a) FFA and lysolecithin, perhaps together with other lipid components, may have synergistic cytotoxic effects. We consider this possibility unlikely. (b) Unusual species of FFA and/or lysolecithin not present in the commercial preparations used in our liposome cytotoxicity studies may account for the cytotoxicity of lipolyzed TG-rich lipoproteins. This possibility will be explored further. $(c)$ The physical chemical organization of the surface remnants of lipolyzed TG-rich lipoproteins may increase the sensitivity of macrophages to the cytotoxic effects of FFA, lysolecithin, or other compounds localized to the surface remnants such as 
Table I. Relationship of Oxidized Lipids to Cytotoxicity

\begin{tabular}{|c|c|c|c|c|c|}
\hline \multirow[b]{2}{*}{ Lipoproteins } & \multirow[b]{2}{*}{ Level of oxidized lipids } & \multicolumn{4}{|c|}{$\begin{array}{c}\text { Cytotoxicity of VLDL } \\
\text { or serum ( } \mu \mathrm{g} \\
\text { cholesterol/ml medium) }\end{array}$} \\
\hline & & 10 & 25 & 50 & 100 \\
\hline & $n M M D A / m g$ cholesterol & \multicolumn{4}{|c|}{$\begin{array}{l}\text { Cell viability } \\
\text { (\% of control) }\end{array}$} \\
\hline Control VLDL & 4.54 & 83 & 85 & 78 & 75 \\
\hline Lipolyzed VLDL & 3.65 & 18 & 0 & 0 & 0 \\
\hline Control HTG serum & 2.10 & 90 & 89 & 87 & 83 \\
\hline Lipolyzed HTG serum & 1.90 & 10 & 0 & 0 & 0 \\
\hline \multicolumn{6}{|l|}{ Lipolyzed HTG serum } \\
\hline$+\mathrm{BHT}$ & 1.79 & 6 & 0 & 0 & 0 \\
\hline
\end{tabular}

Values of MDA are the means of duplicate determinations.

peroxidized lipids. This is an appealing possibility considering the ability of HDL to provide protection against cytotoxicity and change the physical organization of surface remnants of lipolyzed TG-rich lipoproteins. $(d)$ Lipid components other than FFA and lysolecithin, may be the primary mediators of cytotoxicity in the lipolyzed TG-rich lipoproteins.

Our data do not support peroxidized lipids as the cause of lipolysis-induced cytotoxicity because lipolysis has no measurable effect on the level of oxidized lipids in VLDL and/or HTG serum and inclusion of antioxidant (BHT) during lipolysis and dialysis of samples failed to inhibit cytotoxicity (Table I). However, we can not rule out at present the possibility that lipolyzed VLDL is more susceptible to cell-mediated oxidation than control VLDL.

It has long been suspected that lipolytic remnants of TGrich lipoproteins in animals on an atherogenic diet are responsible for the development of atherosclerosis in these animals (10). Several studies by Kruth $(33,34)$ have shown that early atherosclerotic lesions in both humans and experimental animals contain numerous particles rich in unesterified cholesterol but poor in cholesteryl ester. These particles are seen even before the appearance of foam cells in the lesions. Recent studies by Simionescu et al: (35) showed that prefoam cell atherosclerotic lesions in cholesterol-fed rabbits contain numerous liposome-like intimal vesicles rich in phospholipid and unesterified cholesterol. Although these authors did not deter- mine the origin of these vesicles, the morphology and lipid composition of the vesicles are suggestive of the TG-rich lipoprotein surface remnants that we propose are cytotoxic and foam cell inducing both in vitro and in vivo. Similar liposome-like intimal lipid deposits have been reported before in both humans (36) and other animal models of atherosclerosis, such as baboons and dogs $(37,38)$. Furthermore, the lipid incusions in the foam cells of both humans and animal models of atherosclerosis have been reported to contain liposome or surface remnant-like myelin bodies $(36,37)$.

Humans spend a great deal of time, albeit episodic, in the postprandial HTG state. We showed in Fig. 3 that postprandial serum, but not fasting serum, when lipolyzed in vitro, is cytotoxic to cultured macrophages (Fig. 3). Lipolysis of dietary-induced TG-rich lipoproteins occurs to a large extent at the LpL binding sites on the endothelial surface of blood vessels. Although not much is known about the density of $\mathrm{LpL}$ binding sites on the endothelial surface of large-to-mediumsize arteries where the atherosclerotic plaque occurs, there is a definite possibility that an episodic concentration gradient of potentially atherogenic TG-rich remnants exists at the endothelial surface of these arteries. Under these conditions, the remnant to HDL ratio at the endothelial surface would be expected to be much higher than in the circulation. It may be significant that endothelial cells have recently been reported to have a higher concentration of the putative HDL receptor than any other cell type examined (39). Perhaps a function of the HDL receptor is to raise the HDL concentration at the endothelial cell surface to match that of cytotoxic TG-rich remnants.

A surface remnant model for atherogenesis has three interesting implications: (a) recent studies (40) support the notion that early atherosclerosis in humans begins in regions of the coronary artery subject to low hemodynamic shear stress. It is well known that arterial branch points, for example, the aortic intercostal ostia, are highly susceptible to early atherosclerotic plaques. A simple explanation for this correlation is that there is a concentration gradient of atherogenic (i.e., cytotoxic) substance(s) extending outward from the endothelial surface of the arterial wall; high shear stress would be expected to disrupt this gradient.

(b) Inherited or acquired regional differences in density and/or structure of the LpL binding sites or the HDL receptor on the endothelial surfaces of large-to-medium-size arteries could explain the otherwise unexplained individual variations

Table II. Cytotoxicity of Control and Lipolyzed VLDL to Various Cultured Cells

\begin{tabular}{|c|c|c|c|c|c|c|c|c|}
\hline \multirow[b]{2}{*}{ Cells } & \multicolumn{3}{|c|}{ Control VLDL } & \multicolumn{5}{|c|}{ Lipolyzed VLDL } \\
\hline & \multicolumn{8}{|c|}{$\mu \mathrm{g}$ cholesterol/ml medium } \\
\hline & \multicolumn{8}{|c|}{ Cell viability (\% of control) } \\
\hline Mouse peritoneal macrophages & 92 & 93 & 89 & 9 & 0 & 0 & - & 0 \\
\hline Human macrophages & 90 & 92 & 90 & 30 & 11 & 0 & - & 0 \\
\hline Human blood monocytes & 100 & 100 & 98 & 95 & 94 & 90 & - & 90 \\
\hline J 774 macrophages & 93 & 95 & 92 & 94 & 92 & 87 & 23 & 0 \\
\hline Human endothelial cells* & 100 & 100 & 100 & 100 & 100 & 100 & 0 & 0 \\
\hline Human fibroblasts. & 100 & 100 & 100 & 100 & 100 & 100 & 100 & 100 \\
\hline Rat cardiac myocytes & 100 & 100 & 100 & 100 & 100 & 100 & 100 & 100 \\
\hline
\end{tabular}

* Manuscript on studies of endothelial cells submitted to Arteriosclerosis (1988). 
observed in the location and severity of atherosclerotic plaques in the human arterial tree. Also explained could be the differing susceptibility of saphenous vein versus internal mammary artery coronary artery bypass grafts to accelerated atherosclerosis.

(c) Abnormalities in postprandial lipoprotein structure and metabolism may be at least as atherogenic as abnormalities in fasting lipoproteins. Furthermore, the surface remnant hypothesis suggests that an individual whose fasting lipoprotein levels are unresponsive to a high-fat diet may have an increased rate of development of atherosclerosis compared with another individual with the same lipoprotein profile but on a low fat diet. Postprandial predictions of the surface remnant hypothesis are currently being tested in our laboratory.

A number of studies have shown that VLDL from HTG plasma is cytotoxic to cultured endothelial cells $(41,42)$. We have observed that circulating TG-rich lipoproteins isolated from certain HTG individuals are cytotoxic to macrophages even in the absence of prior in vitro lipolysis, and that the cytotoxicity of these lipoprotein fractions is further increased by in vitro lipolysis (data not shown). This is additional evidence that the cytotoxicity of remnant lipoproteins may be a factor in vivo.

In conclusion, as a working hypothesis we suggest that vesicular cytotoxic surface remnants of lipolyzed VLDL and chylomicrons may represent a major class of atherogenic lipoproteins that are exacerbated during postprandial hyperlipidemia. Further, we suggest that inhibition of the cytotoxicity of these remnants may be one important way that HDL prevents atherosclerosis. An appealing aspect of this hypothesis is that it can account for several unexplained features of atherosclerosis, such as anatomic differences in susceptibility to atherosclerosis in the vascular tree and the vesicular nature of lipid deposits in early atherosclerosis.

\section{Acknowledgments}

We are indebted to Dr. Francois M. Booyse and Dr. Mike Speidel for culturing human umbilical vein endothelial cells and testing the cytotoxic effect of lipolyzed VLDL to the endothelial cells in their laboratories. We wish to thank Dr. Larry Bugalsky, Dr. Marianne Egan, and Dr. Henning Birkendal for providing cultured rat cardiac myocytes, human monocytes and macrophages, or human skin fibroblasts and Dr. Jack Geer, Dr. Jim Christner, Dr. David Garber, and Dr. Margie Ray for helpful discussion.

This work was supported in part by grant HL-33500 and HL-37833 from the National Institutes of Health and by the Atherosclerosis Research Unit.

\section{References}

1. Kannel, W. B., W. P. Castelli, T. Gordon, and P. M. McNamara. 1971. Serum cholesterol, lipoproteins, and the risk of coronary heart disease. Ann. Intern. Med. 74:1-12.

2. Kannel, W. B., W. P. Castelli, and T. Gordon. 1979. Cholesterol in the predition of atherosclerotic disease. New perspectives based on the Framingham study. Ann. Intern. Med. 90:85-91.

3. Kostner, G. M., P. Avogaro, P. G. Cazzolato, E. Marth, G. Bittolo-Bon, and G. B. Qunici. 1981. Lipoprotein Lp(a) and the risk for myocardial infarction. Atherosclerosis. 51:51-61.

4. Scow, P. O., E. J. Branchett-Machie, and L. C. Smith. 1976. Role of capillary endothelium in the clearance of chylomicrons: a model for lipid transport from blood by lateral diffusion in cell membranes. Circ. Res. 39:149-162.
5. Patsch, J. R., A. M. Gotto Jr., T. Olivercrona, and S. Eisenberg. 1978. Formation of high density lipoprotein-2-like particles during lipolysis of very low density lipoproteins in vitro. Proc. Natl. Acad. Sci. USA. 75:4519-4523.

6. Chait, A., J. D. Brunzell, J. J. Albers, and W. R. Hazzard. 1977. Type-III hyperlipoproteinaemia (remnant removal disease): insight into the pathogenic mechanism. Lancet. i:1176-1178.

7. Morganroth, J., R. I. Levy, and D. S. Fredrickson. 1975. The biochemical, clinical, and genetic features of type III hyperlipoproteinemia. Ann. Intern. Med. 82:158-174.

8. Nestel, P. J., N. H. Fidge, and M. H. Tan. 1982. Increased lipoprotein-remnant formation in chronic renal failure. N. Engl. J. Med. 307:329-333.

9. Tatami, R., H. Mabuchi, K. Ueda, R. Ueda, T. Hara, T. Kametani, S. Ito, J. Koizumi, M. Ohta, S. Miyamoto, A. Nakayama, H. Kanaya, H. Oiwake, A. Genda, and R. Takeda. 1981. Intermediatedensity lipoprotein and very low density lipoprotein in angiographically determined coronary artery disease. Circulation. 64:1174-1184.

10. Zilversmit, D. B. 1973. A proposal linking atherogenesis to the interaction of endothelial lipoprotein lipase with triglyceride-rich lipoproteins. Circ. Res. 33:633-637.

11. Goldstein, J. L., Y. K. Ho, M. S. Brown, T. L. Innerarity, and R. W. Mahley. Cholestrylester accumulation in macrophages resulting from receptor-mediated uptake and degradation of hypercholesterolemic canine B-very low density lipoproteins. J. Biol. Chem. 255:1839-1848.

12. Mahley, R. W., T. L. Innerarity, M. S. Brown, Y. K. Ho, and J. L. Goldstein. 1980. Cholesterylester synthesis in macrophages: stimulation by B-very low density lipoproteins from cholesterol-fed animals of several species. J. Lipid Res. 21:970-980.

13. Ostlund-Lindqvist, A. M., S. Gustafson, P. Lindqvist, J. L. Witztum, and A. C. Little. 1983. Uptake and degradation of human chylomicrons by macrophages in culture. Role of lipoprotein lipase. Arteriosclerosis. 3:433-440.

14. Van Leten, B. J., A. M. Fogelman, R. L. Jackson, S. Shapiro, M. E. Haberland, and P. E. Edwards. 1982. Receptor mediated uptake of remnant lipoproteins by cholesterol loaded human monocyte-macrophages. J. Biol. Chem. 260:8783-8788.

15. Chung, B. H., J. P. Segrest, J. T. Cone, J. Pfau, J. C. Geer, and L. A. Duncan. 1981. High resolution plasma lipoprotein cholesterol profiles by a rapid, high volume, semi-automated method. J. Lipid Res. 22:1003-1014.

16. Chung, B. H., T. Wilkinsonm, J. C. Geer, and J. P. Segrest. 1980. Preparative and quantitative isolation of plasma lipoproteins: rapid, single, discontinuous density gradient ultracentrifugation in a vertical rotor. J. Lipid Res. 21:284-291.

17. Iverius, P. H., and A. M. Ostlund-Lindqvist. 1976. Lipoprotein lipase from bovine milk: isolation procedure, chemical characterization, and molecular weight analysis. J. Biol. Chem. 251:7791-7795.

18. Edelson, P. J., and B. A. Cohn. 1976. Purification and cultivation of monocytes and macrophages. In In Vitro Method in Cell-mediated Immunity and Immunology. B. R. Bloom and J. R. David, editors. Academic Press, Inc., New York. 333-340.

19. Recalde, H. 1984. A simple method of obtaining monocytes in suspension. J. Immunol. Methods. 69:71-77.

20. Philips, H. J. 1973. Dye exclusion tests for cell viability. In Tissue Culture: Method and Application. R. F. Kruse and M. K. Patterson, editors. Academic Press, New York. 406-408.

21. Itaya, K. 1977. A more sensitive and stable colorimetric determination of free fatty acids in blood. J. Lipid Res. 18:16-20.

22. Kosuki, H., and K. Kikugawa. 1985. Thiobarbituric acid reaction of aldehydes and oxidized lipids in glacial acetic acid. Lipids. 20:915-921.

23. Stewart, J. C. M. 1980. Colorimetric determination of phospholipids with ammonium ferrothianate. Anal. Biochem. 104:10-14.

24. Skipski, V. P., R. F. Peterson, and M. Barclay. 1964. Quantitative analysis of phospholipids by thin-layer chromatography. Biochem. J. 90:374-378. 
25. Oconnel, P. B. H., and C. J. Brady. 1977. Polyacrylamide gel with modified cross-linkages. Anal. Biochem. 76:63-73.

26. Chung, B. H., J. T. Cone, and J. P. Segrest. Defective in vitro liplysis of type IV hyperlipidemic human plasma by purified bovine milk lipoprotein lipase. J. Biol. Chem. 257:7472-7480.

27. Hessler, J. H., D. W. Morel, L. J. Lewis, and G. M. Chisolm. 1983. Lipoprotein oxidation and lipoprotein-induced cytotoxicity. $A r$ teriosclerosis. 4:357-364.

28. Morel, D. W., J. R. Hessler, and G. M. Chisolm. 1983. Low density lipoprotein cytotocicity induced by free radical peroxidation of lipid. J. Lipid Res. 24:1070-1076.

29. Nilsson-Ehle, P., A. S. Garfinkle, and M. S. Schotz. 1980. Lipolytic enzymes and plasma lipoprotein metabolism. Annu. Rev. Biochem. 49:667-693.

30. Jackson, R. L., and A. M. Gotto, Jr. 1976. Hypothesis concerning membrane structure, cholesterol, and atherosclerosis. Atherosclerosis Rev. 1:1-22.

31. Abrams, A., M. T. Speidel, F. M. Booyse, and J. P. Segrest. 1988. Cytotoxicity of lipolyzed very low density lipoproteins and inhibition of cytotoxicity by high density lipoproteins to endothelial cells in vitro. Fed. Proc. 5:4313.

32. Ross, R., and J. A. Glomset. 1976. Pathogenesis of atherosclerosis. N. Engl. J. Med. 295:295-304.

33. Kruth, H. S. 1985. Subendothelial accumulation of unesterified cholesterol. An early event in atherosclerotic lesion development. Atherosclerosis. 57:337-341.

34. Kruth, H. S., and D. L. Fry. 1984. Histochemical detection of unesterified cholesterol within human atherosclerotic lesion using the fluorescent probe filifin. Exp. Mol. Pathol. 40:288-29.

35. Simionescu, V., E. Vasile, F. Lupu, G. Popescu, and M. Simionescu. 1986. Prelesional event in atherogenesis. Accumulation of extracellular cholesterol-rich liposomes in the arterial intima and cardiac valves of the hyperlipidemic rabbit. Am. J. Pathol. 123:109-125.

36. Geer, J. C. 1965. Fine structure of human aortic intimal thickening and fatty streaks. Lab. Invest. 14:1764-1783.

37. Geer, J. C. 1965. Fine structure of canine experimental atherosclerosis. Am. J. Pathol. 47:241-269.

38. Geer, J. C., C. Catsulis, H. C. McGill, and J. P. Strong. 1968. Fine structure of the baboon aortic fatty streak. Am. J. Pathol. 52:265-285.

39. Graham, D. L., and J. F. Oram. 1986. Identification of the high density lipoprotein receptor in cultured cells by ligand blotting. Arteriosclerosis. 6:537a. (Abstr.)

40. Ku, D. N., D. P. Giddens, C. K. Zarins, and S. Glagov. 1985. Pulsatile flow and atherosclerosis in human carotid bifurcation. Positive correlation between plaque location and low and oscillating shear stress. Arteriosclerosis. 5:293-302.

41. Gianturco, S. H., S. G. Eskin, L. T. Navarro, C. T. Lahart, L. C. Smith, and A. M. Gotto, Jr. 1980. Abnormal effects of hypertriglyceridemic very low density lipoproteins lipoproteins on 3-hydroxy-3methylglutaryl Co A reductase activity and vialbility of cultured bovine aortic endothelial cells. Biochim. Biophys. Acta. 618:143-152.

42. Arbogast, B. W., L. R. Gill, and H. A. Schwertner. 1985. New Protective factor in coronary artery disease. Very low density lipoprotein toxicity-preventing activity. Atherosclerosis. 57:75-86. 